\title{
Enabling Cost-Based Support Structure Optimization in Laser Powder Bed Fusion of Metals
}

\author{
K. BARTSCH (iD) ${ }^{1,2}$ and C. EMMELMANN ${ }^{1}$ \\ 1.-Institute of Laser and System Technologies, Hamburg University of \\ Technology, Hamburg, Germany. 2.—e-mail: katharina.bartsch@tuhh.de
}

Support structures are essential to laser powder bed fusion (PBF-LB/M). They sustain overhangs, prevent distortion, and dissipate process-induced heat. Their removal after manufacturing is required, though, increasing the overall costs. Therefore, optimization is important to increase the economic efficiency of PBF-LB/M. To enable optimization focused on the support structures' costs, a cost model is developed. The whole production process, including the design, manufacturing, and post-processing of a part, is considered by deriving formulas for the individual costs. The cost model is applied to a previously developed benchmark procedure. Additionally, a case study investigating different support layout strategies is conducted.

\section{INTRODUCTION}

Laser powder bed fusion of metals (PBF-LB/M), also known as selective laser melting (SLM), is gaining importance as a manufacturing process in industries with huge demands for lightweight or individualized designs, e.g., aviation, automotive, or medical engineering. Despite offering high geometrical flexibility and functionality, $\mathrm{PBF}-\mathrm{LB} / \mathrm{M}$ is characterized by some disadvantages, such as high thermal gradients resulting in critical residual stresses and a restriction on the angle of overhanging features to the build platform, ranging from $30^{\circ 1}$ to $45^{\circ}{ }^{2}$ To deal with these challenges, support structures are applied to the manufacturing setup. They are auxiliary structures not belonging to the functional part and sustain overhangs, fixate the part in space to prevent distortion due to residual stresses, as well as dissipate process-induced heat. ${ }^{3}$ Because the support structures do not belong to the part, they have to be removed after manufacturing, increasing the overall costs by additional material consumption, design, and post-processing efforts.

To decrease the production costs and enhance the manufacturing capabilities of the PBF-LB/M process, support structure optimization is receiving increasing attention in research. While most studies

(Received September 27, 2021; accepted November 16, 2021; published online December 16, 2021) claim to aim for cost minimization, few actually consider the overall costs induced by support structures but optimize for one of the parameters influencing these. The most utilized parameter is the support structure volume, which directly affects material consumption and manufacturing time. The second parameter targeted in optimization is the ease of support structure removal. This greatly influences the overall costs because it is often done manually. ${ }^{4}$

Langelaar (Refs. 5-7) introduced the approach of directly addressing support structure cost in support structure optimization. Utilizing topology optimization to optimize part, support structure, and later on part orientation on the build platform at the same time, Langelaar included the support costs in the optimization problem formulation as constant factors related to the support structure volume for material consumption as well as the support-part interface region volume for support structure removal, respectively. In (Ref. 6), distinction is also made between a standard support structure cost region, where support structures are needed for successful manufacturing, and a part translation region, which may be introduced to avoid building the part directly on the build platform by connecting both via support structures to facilitate easy part removal.

Kuo et al. (Ref. 8) also propose a topology optimization approach to enhance support structure design regarding support structure removal and 
costs. First, a repulsion index is introduced to the optimization problem formulation, leading to a perforated support-part interface region for easy removal with fewer residuals. In a second step, the costs due to the additional build time are considered by the addition of a cost-weighting factor. The costweighting factor is defined such that support structures far from part features as well as support structures widely spread across the design domain are punished to reduce travel time.

In (Ref. 9), parametric support structure designs with tree-like topology as well as lattice support structures are developed and experimentally evaluated. In terms of support structure costs, the scan time and support structure weight are used as cost indicators rather than performing a detailed cost calculation. A similar approach is followed by (Ref. 10), who investigate various support structure parameters experimentally to develop design guidelines for support structures. Here, support structure volume and removal time are evaluated as cost indicators.

In conclusion, whenever support structure costs are directly addressed in an optimization study, they are approximated by one or two factors or indicators. Furthermore, as there is no benchmark standard to evaluate support structure performance and optimization results yet, the overall support structure costs are almost not considered at all in optimization efforts. To advance the integration of costs into support structure optimization, a support structure cost model for PBF-LB/M is developed and added to the benchmark procedure proposed in previous work. ${ }^{11}$ That way, it is possible to compare different support structure designs in terms of costs. Furthermore, the application of the developed cost model to evaluate different support strategies is demonstrated in a case study. In the end, an outlook is given regarding needed future steps to enable the direct integration of support structure costs into optimization approaches.

\section{COST MODELING FOR PBF-LB/M}

As no support structure cost model has been published yet to the authors' knowledge, there is no previous work to build on. Therefore, cost models for the whole $\mathrm{PBF}-\mathrm{LB} / \mathrm{M}$ process are analyzed to choose a suitable basis for the support structure cost model development. Afterwards, the influence of support structures on the respective cost parameters is determined and assembled into a cost model covering the complete manufacturing process.

In $\mathrm{PBF}-\mathrm{LB} / \mathrm{M}$, a part is built by selectively melting consecutive powder layers of a metal alloy by a laser beam, creating a 3D part from 2D layers. The process consists of five main steps: First, the CAD geometry of the part is created. In the second step, the 3D data have to be prepared by positioning them in the build envelope, adding support structures if necessary, slicing the 3D geometry into defined 2D layers, and generating the respective machine code. After data and machine preparation, the actual manufacturing takes place. Here, a powder layer is deposited and exposed to laser radiation according to the machine code generated in the previous process step; last, the build platform is lowered to enable the repetition of the cycle. This is repeated until the part is finished. After manufacturing, the build platform is unpacked and the post-processing phase starts. Depending on the material, stress relief heat treatment may be required. After detaching the part from the build platform, support structures are removed. As there may be residuals, the part surface can require additional finishing.

Even though PBF-LB/M is increasingly applied in industry, it is still not an established technology. ${ }^{12,}{ }^{13}$ Modeling the cost of PBF-LB/M is an important contribution to determine whether a business case's economics are positively influenced by the application of PBF-LB/M. To enable this consideration, various approaches have been published to give an accurate cost estimate. Except for (Ref. 14), who studied a buy scenario, models deal with make scenarios. While early publications introduced methods to calculate the cost of real use cases, ${ }^{15-20}$ the aim of economic studies has now shifted to predicting the cost of a given part, allowing for comparison with conventional manufacturing techniques. ${ }^{12}$ 13, $21-24$ The span of included process steps varies from manufacturing only, ${ }^{14}, 16,19$ not considering data preparation or the post-processing of parts, to complete life cycle cost assessment. 2,23 If support structures are considered in these models, they are integrated as a factor or by their volume, mainly used for material consumption calculation. ${ }^{24}$ included the time necessary for the support structure removal, while (Ref. 19) even considered adjusted process parameters for support structures.

To compare optimization approaches, e.g., by a benchmark procedure, a calculative model is needed which includes the whole support structure life cycle from design in the data preparation phase, manufacturing, and removal of the support structures as well as possible residuals on the part surface in the post-processing step. These criteria are met by the recent model of (Ref. 18). Based on the model of (Ref. 16), he structured the costs of $\mathrm{PBF}-\mathrm{LB} / \mathrm{M}$ into material and manufacturing costs. The material costs consist of the part material consumption, support material consumption, as well as possible powder losses due to trapped powder or agglomeration. The manufacturing costs are further split into the preparation costs, build process costs (machine and consumables), postprocessing costs (heat treatment, detachment, support removal, surface finish), and costs associated with quality assurance. This model includes support 
structures at two points: first as a factor estimating support structure material consumption and then by accounting for the time needed for removal.

\section{DEVELOPMENT OF COST MODEL FOR SUPPORT STRUCTURES IN PBF-LB/M}

The cost model structure of (Ref. 18) is used to analyze the fields of support structure influence on the overall part costs. The material costs are directly affected because support structures require material to be built. Additionally, powder can be trapped within support structures, e.g., lattice structures with low perforation. The amount of trapped powder is extremely difficult to evaluate, which is why the entrapment of powder is not included in the support structure cost model. During the manufacturing process, support structures influence several process steps. They have to be designed during data preparation and lead to increased build time, since their slices have to be exposed, too. When detaching the parts from the build platform, e.g., by wire eroding, they can also increase the processing time when the part is orientated in a way that support structures increase the overall eroding distance. Last, support structures need to be removed, causing direct costs and increasing the finishing time. Other process steps such as machine preparation and clean-up as well as heat treatment are not affected significantly, though.

The costs due to support structures of a single part are categorized regarding the process phase to allow for detailed assessment: design phase $\left(C_{D}\right)$, manufacturing phase $\left(C_{M}\right)$, and post-processing phase $\left(C_{P}\right)$. The overall support structure costs $C_{S}$ consist of the sum of each phase's cost.

$$
C_{S}[€]=C_{D}[€]+C_{M}[€]+C_{P}[€]
$$

The detailed costs of the three phases are determined in the following sections. Within the different cost factors, three general types of cost are identified. Since these occur in more than one phase, they are briefly described here. Taking on the activitybased approach, each consists of a time component as well as an hourly cost rate. The first type is operator cost $\left(C_{O}\right)$, which denotes the involvement of personnel (engineer, technician, or similar). The cost is composed of the labor time $t_{L}$ and the hourly wage, including the gross wage of the employee $c_{w, g}$ as well as the incidental wage $c_{w, i}$.

$$
C_{O}[€]=t_{L}[h] *\left(c_{w, g}\left[\frac{€}{h}\right]+c_{w, I}\left[\frac{€}{h}\right]\right)
$$

If the gross wage is given as annual value, it can be translated to an hourly value by mapping the annual gross wage from the workdays per year $d_{\text {Year }}$ to the workdays per week $d_{W e e k}$, because the work hours per week $t_{W e e k}$ are usually known together with the annual gross wage:

$$
c_{w, g}\left[\frac{€}{\mathrm{~h}}\right]=\frac{c_{w, g}\left[\frac{€}{\mathrm{a}}\right]}{d_{\text {Year }}\left[\frac{\mathrm{d}}{\mathrm{a}}\right] * \frac{t_{\text {Wee }}\left[\frac{\mathrm{h}}{\mathrm{week}}\right]}{d_{\text {Week }}\left[\frac{\mathrm{d}}{\mathrm{week}}\right]}}
$$

The second recurring type of cost is the cost of technical equipment $\left(C_{E}\right)$. It is determined by the capital investment $C_{I}$ and the amortization period $t_{a}$. Additionally, it is referred to the time in use $t_{U E}$ and the overall utilization rate $u_{E}$ of the respective equipment to determine the exact share in costs of the equipment.

$$
C_{E}[€]=\frac{t_{U E}[\mathrm{~h}]}{u_{E}\left[\frac{\mathrm{h}}{\mathrm{a}}\right]} * \frac{C_{I}[€]}{t_{a}[\mathrm{a}]}
$$

The last general cost type is the room $\operatorname{cost} C_{R}$ due to the renting of office or workshop space. It is composed of the actual rent $c_{R R}$ as well as the operating costs $c_{R O}$, which include additional expenses for electricity, heat, furniture, and maintenance. These costs are related to the area of space required. In the case of owned property, the rent can be substituted by an equipment cost (Eq. 4) consisting of the investment and amortization period of the property. Similar to the equipment cost, the room cost is related to the time in use $t_{U R}$ and the overall utilization $u_{R}$ of the room.

$$
C_{R}[€]=\frac{t_{U R}[h]}{u_{R}\left[\frac{h}{a}\right]} * A[\mathrm{~m}] *\left(c_{R R}\left[\frac{€}{\frac{\mathrm{m}^{2}}{a}}\right]+c_{R O}\left[\frac{€}{\frac{€}{a}}\right]\right)
$$

The annual expenses for rent and operating costs may be determined by summing up the monthly payments:

$$
\begin{aligned}
& c_{R R}\left[\frac{€}{\frac{€}{\mathrm{a}}}\right]=c_{R R}\left[\frac{\frac{€}{\mathrm{~m}^{2}}}{\mathrm{month}}\right] * 12\left[\frac{\mathrm{month}}{\mathrm{a}}\right] \\
& c_{R O}\left[\frac{€}{\frac{\mathrm{m}^{2}}{\mathrm{a}}}\right]=c_{R O}\left[\frac{€}{\mathrm{~m}^{2}}\right] * 12\left[\frac{\mathrm{month}}{\mathrm{m}}\right]
\end{aligned}
$$

\section{Design Phase Costs}

For the design of the support structures during data preparation prior to manufacturing, an engineer or technician commonly uses a specialized preparation software for a specific time. Even when optimizing support structures, it is done with the help of software. Accordingly, the costs of the design phase $C_{D}$ consist of the cost for the operator $\left(C_{O, D}\right)$, the necessary equipment $\left(C_{E, D}\right)$, and the required office space $\left(C_{R, D}\right)$.

$$
C_{D}[€]=C_{O, D}[€]+C_{E, D}[€]+C_{R, D}[€]
$$

Notice that the time to position a part on the build platform is not included, since this step is assumed independent from the support structures. As computational methods such as topology optimization 
may require extensive computational times, where the operator does not need to be present at the computer, different time intervals have to be applied. Therefore, the operator cost is determined according to Eq. (2) with the time of operator occupation $t_{O D}$, while the equipment and office room costs are calculated using the time of equipment occupation $t_{E . D}$ following Eqs. (4) and (5), respectively. When the standard support structures implemented in the data preparation software are used, $t_{O, D}=t_{E, D}$ applies.

The equipment is further composed of the software (SW) and the computer hardware (HW) to run the software. While the hardware cost is determined as indicated in Eq. (4), software cost usually can occur in two different ways: Either it is bought and can be treated as general equipment or it is distributed with a licensing scheme. In this case, the license cost $c_{S W}$ can directly be used for the software cost instead of the investment cost related to the amortization period. Because the licensing scheme is the common way of distribution, it is prioritized in this work.

In summary, the different cost items of the support structure design costs are calculated as follows (units only indicated when differing from the general definitions of Eqs. (2-5)):

$$
\begin{gathered}
C_{O, D}[€]=t_{O, D} *\left(c_{w, g, D}+c_{w, i, D}\right) \\
C_{E, D}[€]=\frac{t_{E, D}}{u_{S W}} * c_{S W}\left[\frac{€}{\mathrm{a}}\right]+\frac{t_{E, D}}{u_{H W}} * \frac{C_{I, H W}}{t_{a, H W}} \\
C_{R, D}[€]=\frac{t_{E, D}}{u_{O}} * A_{O} *\left(c_{R R, O}+c_{R O, O}\right)
\end{gathered}
$$

\section{Manufacturing Phase Costs}

The manufacturing costs are split into the material costs $\left(C_{M . M}\right)$ and the production costs $\left(C_{M . P}\right)$. For the material costs, the raw material consumption as well as the possibility to sell detached support structures as scrap metal is accounted for. The difference in prices of both cost items is related to the weight of the support structures.

$$
\begin{aligned}
C_{M, M}[€]= & \rho\left[\frac{\mathrm{kg}}{\mathrm{m}^{3}}\right] * V\left[\mathrm{~m}^{3}\right] \\
& *\left(c_{\text {Mat }}\left[\frac{€}{\mathrm{~kg}}\right]-c_{\text {Scrap }}\left[\frac{€}{\mathrm{~kg}}\right]\right)
\end{aligned}
$$

The production costs include all machine-related costs of the manufacturing system, i.e., machine operating costs as well as consumables (filter, gas, energy) necessary for the PBF-LB/M process. For the machine costs, the equipment, room, and service $\operatorname{cost}\left(c_{M, S e r}\right)$ of maintenance are summed up:

$$
\begin{aligned}
C_{P, M, M}[€]= & \frac{t_{B}}{u_{M}} * \frac{C_{I, M}}{t_{a, M}}+\frac{t_{B}}{u_{M}} * A_{M} *\left(c_{R R, M}+c_{R O, M}\right) \\
& +\frac{t_{B}}{u_{M}} * c_{M, S e r}\left[\frac{€}{\mathrm{a}}\right]
\end{aligned}
$$

A critical factor in Eq. (12) is the build time $t_{B}$. First, the support structure volume has to be built additionally to the part volume. Second, sometimes support structures are used to set off the part from the build platform, e.g., to facilitate easy removal. In this case, support structures cause extra layers to be manufactured which need to be included into the build time. The exact number of additional layers is derived from the difference in build height due to offset by support structures $\Delta h$ and the layer thickness $t h$. For each layer, the time for depositing a new powder layer $t_{P}$ as well as possible system delay $t_{D e l}$ in between layers for adequate cooling of the previous layer contributes to the build time because of support structures.

$$
t_{B}[\mathrm{~h}]=\frac{V\left[\mathrm{~m}^{3}\right]}{\dot{M}\left[\frac{\mathrm{m}^{3}}{\mathrm{~h}}\right]}+\frac{\Delta h[\mathrm{~m}]}{t h[\mathrm{~m}]} *\left(t_{P}[\mathrm{~h}]+t_{D e l}[\mathrm{~h}]\right)
$$

If the melt rate $\dot{M}$ is not known, it can be derived from the process parameter scan velocity $\left(v_{S}\right)$, hatch distance $d_{h}$, layer thickness $t h$, and number of lasers $\left(n_{L}\right)$ the machine is equipped with or utilized in the build job if the build platform is not fully packed. Here, an important assumption is the equal distribution of volume in the build chamber, i.e., all utilized lasers operate simultaneously.

$$
\dot{M}\left[\frac{\mathrm{m}^{3}}{\mathrm{~h}}\right]=v_{S}\left[\frac{\mathrm{m}}{\mathrm{h}}\right] * d_{h}[\mathrm{~m}] * t h[\mathrm{~m}] * n_{L}[-]
$$

The costs due to consumables include the cost of gas filter $\left(C_{P, F, M}\right)$, the processing gas itself $\left(C_{P, G, M}\right)$, as well as the energy supplying the machine $\left(C_{P, E, M}\right)$. While the filter is treated as standard equipment cost, gas and energy costs are determined directly from the market price. Please note that Eqs. (15-17) assume the part investigated to be the only part manufactured in the build job. If this is not the case, the costs due to consumables are to be distributed across all parts manufactured weighted by their respective volume.

$$
\begin{gathered}
C_{P, F, M}[€]=\frac{t_{B}}{u_{M}} * \frac{C_{I, F}}{t_{a, F}} \\
C_{P, G, M}[€]=t_{B} * c_{G}\left[\frac{€}{\mathrm{~h}}\right] \\
C_{P, E, M}[€]=t_{B} * c_{E}\left[\frac{€}{\mathrm{~h}}\right]
\end{gathered}
$$


The gas price may be derived from the gas flow of the machine $\dot{f}_{G}$ and the purchase price $p_{G}$. The same approach can be applied to the energy price by combining the energy consumption of the machine $E$ with the respective purchase price $p_{E}$.

$$
\begin{aligned}
& c_{G}\left[\frac{€}{\mathrm{~h}}\right]=\dot{f}_{G}\left[\frac{\mathrm{m}^{3}}{\mathrm{~h}}\right] * p_{G}\left[\frac{€}{\mathrm{~m}^{3}}\right] \\
& c_{E}\left[\frac{€}{\mathrm{~h}}\right]=E[\mathrm{~kW}] * p_{E}\left[\frac{€}{\mathrm{kWh}}\right]
\end{aligned}
$$

The overall manufacturing costs are calculated by the sum of the various cost items.

$$
\begin{aligned}
C_{M}[€]= & C_{M, M}[€]+C_{P, M, M}[€]+C_{P, F, M}[€] \\
& +C_{P, G, M}[€]+C_{P, E, M}[€]
\end{aligned}
$$

\section{Post-processing Phase Costs}

The post-processing phase includes the detachment from the build platform as well as the support structure removal. Both tasks can be performed in various ways, each one resulting in its own cost structure. The following assumptions are made by the authors: (1) Detachment from the build platform is done by wire eroding. (2) Support structure removal is done manually. Both assumptions may be adjusted to the situation relevant to the user of this cost model.

For wire eroding, only the additional effort due to support structures is of interest, i.e., when the part is oriented in a way that support structures lengthen the eroding distance. The wire eroding costs are derived similar to those of the PBF-LB/M machine and related to the additional time necessary for wire eroding. It is calculated using the distance $d_{W}$ the wire is in contact with the support structures and the velocity during contact $v_{W}$.

$$
t_{W}[\mathrm{~h}]=\frac{d_{W}[\mathrm{~m}]}{v_{W}[\mathrm{~m}]}
$$

Following the cost structure of the production costs, wire eroding costs are differentiated in machine costs and consumable costs, here energy only. The machine costs again consist of equipment, room, and service costs:

$$
\begin{aligned}
C_{P, M, W}[€]= & \frac{t_{W}}{u_{W}} * \frac{C_{I, W}}{t_{a, W}}+\frac{t_{W}}{u_{W}} * A_{W} *\left(c_{R R, W}+c_{R O, W}\right) \\
& +\frac{t_{W}}{u_{W}}+c_{W, S e r}\left[\frac{€}{\mathrm{a}}\right]
\end{aligned}
$$

The energy cost is defined according to Eq. (17):

$$
C_{P, E, W}[€]=t_{W} * c_{E}
$$

During manual removal, a technician uses a workshop as well as different tools for a specific time $t_{R}$. Like the design costs, the removal costs consist of the labor costs of the technician, the equipment cost of the tools, and the room costs of the workshop. Since workshop and tools may be used for other activities as well, the two components are assigned respective utilization factors $u_{W S}$ and $u_{T}$. The corresponding cost items of the removal costs are defined as follows:

$$
\begin{gathered}
C_{P, O, R}[€]=t_{R} *\left(c_{w, g, R}+c_{w, i, R}\right) \\
C_{P, E, R}[€]=\frac{t_{R}}{u_{T}} * \frac{C_{I, T}}{t_{a, T}} \\
C_{P, R, R}[€]=\frac{t_{R}}{u_{W S}} * A_{W S} *\left(c_{R R, W S}+c_{R O, W S}\right)
\end{gathered}
$$

In summary, the post-processing costs equal the sum over the respective cost items.

$$
\begin{aligned}
C_{P}[€]= & C_{P, M, W}[€]+C_{P, E, W}[€]+C_{P, O, R}[€] \\
& +C_{P, E, R}[€]+C_{P, R, R}[€]
\end{aligned}
$$

\section{OPTIMIZATION OF SUPPORT STRATEGY FOR A GIVEN PART}

To demonstrate the application of the support structure cost model to support strategy optimization, i.e., the way of applying a defined support structure to a given part, it is applied to the use case of an aerospace bracket, also known as flight crew rest cabin (FCRC) bracket. The FCRC bracket is scaled to a height of $123 \mathrm{~mm}$ (volume: $20,680 \mathrm{~mm}^{3}$ ) for this study.

\section{Method}

Two different support structure strategies are used to build two brackets (see Fig. 1): For the first part (A), the minimum volume of the support structures is prioritized. The second part (B) focuses on support structure removal by attaching the support structures to the build platform, where they can by detached by wire eroding parallel to the part detachment. Having only one side of the support structure connected to the part is assumed to ease the removal process because less force has to be applied. Additionally, only one interface area must be filed to remove any remains of the support structures after their removal.

The software Materialise Magics Version 23.0 (Materialise NV, Leuven, The Netherlands) was used to design the support structures of the respective parts. To guarantee clean detachment by wire eroding, the parts were set off the build platform by $2 \mathrm{~mm}$ of support structures. Furthermore, the parts are oriented in a way preventing additional wire 


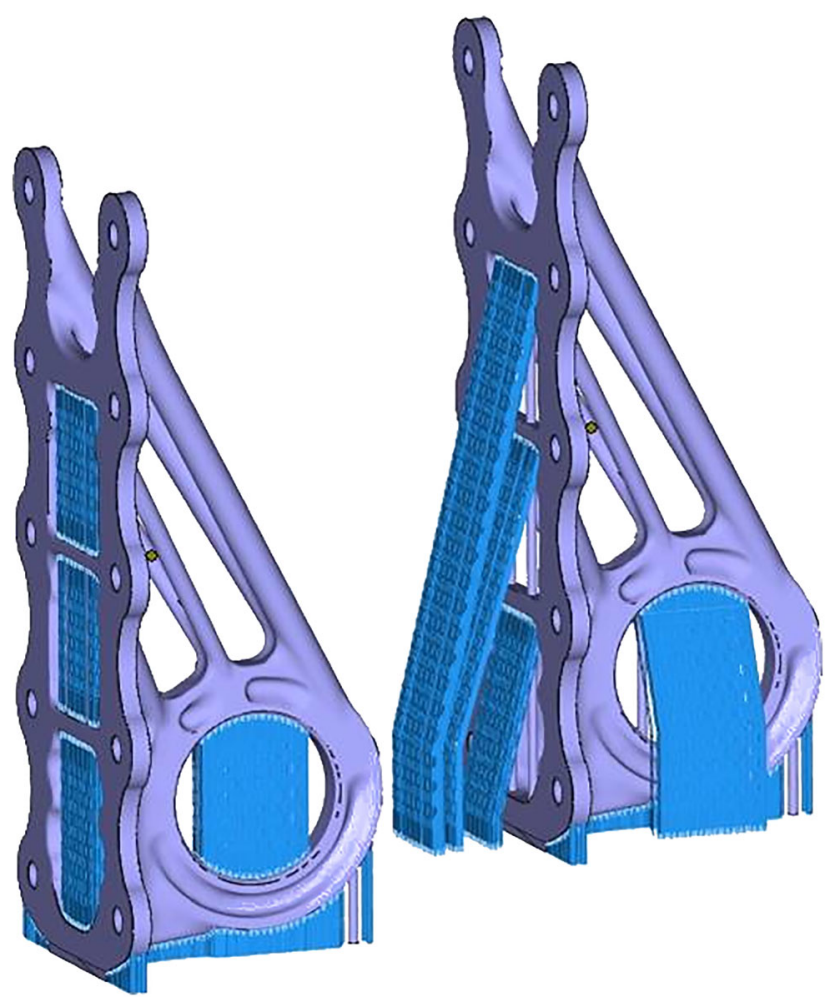

Fig. 1. Support strategies for the FCRC bracket. Left: Minimum volume (part A), right: easier removal (part B).

eroding effort due to support structures. The design time, as well as the removal time, is measured. For the design time, operator time equals the equipment usage time as standard support structure types (block and cone support) are applied, which do not require extra computational time. The removal of the support structures is done by manual work with the help of conventional tools for metal processing. Support structure residuals after removal are filed until there is no influence on the sandblasting process.

The input parameters to the support structure cost model are summarized in Table I and III (see appendix). Assumptions made by the authors are highlighted to give a better understanding of the uncertainties of the cost model. For the PBF-LB/M machine, an EOS M270 (EOS GmbH, Krailing, Germany) is applied. Regarding the wire eroding system, the W-EDM250 TCM (KAAST Werkzeugmaschinen GmbH, Neumünster, Germany) is chosen as example.

\section{Results and Discussion}

Comparing the two different support strategies, the data demonstrate the successful implementation of the respective support strategy goals: While the support structure volume of Part A is nearly half the volume of Part $B$, the time for support structure removal is shorter for Part B. It took more time to design the support structures of Part B, since the volume minimized version is the
Table I. Summary of individual cost model input parameters for support strategy comparison.

\begin{tabular}{lccc}
\hline Parameter & Part A & & Part B \\
\cline { 2 - 2 } $\begin{array}{l}\text { Support volume } \\
V\end{array}$ & $2325 \mathrm{~mm}$ & \\
$\begin{array}{l}\text { Difference height } \\
\Delta h\end{array}$ & & $4115 \mathrm{~mm}^{3}$ \\
$\begin{array}{l}\text { Additional wire eroding distance } \\
d_{\mathrm{W}}\end{array}$ & $2 \mathrm{~mm}$ & \\
$\begin{array}{l}\text { Design time } \\
t_{\mathrm{D}}\end{array}$ & $0 \mathrm{~mm}$ & \\
$\begin{array}{l}\text { Removal time } \\
t_{\mathrm{R}}\end{array}$ & $15 \mathrm{~min}$ & & $20 \mathrm{~min}$ \\
\hline
\end{tabular}

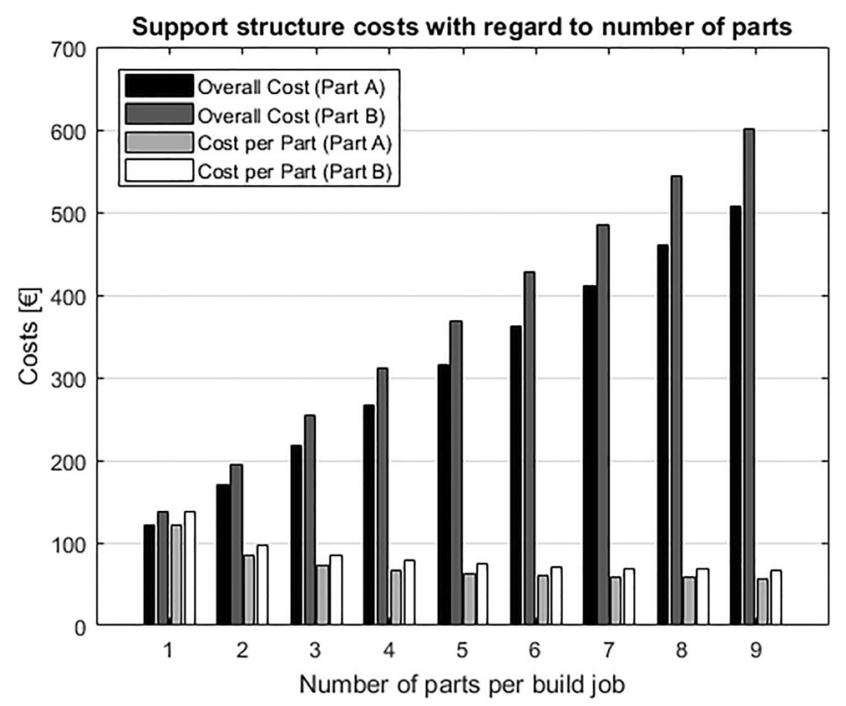

Fig. 2. Support structure cost comparison and development regarding the number of parts on the build platform.

automatic solution of the software, which had to be manually adapted to meet the requirements of Part B.

Figure 2 displays the total support structure cost of the build job as well as the support structure cost per part regarding the number of parts on the build platform. A maximum of nine parts can fit the M270 system. It can be seen that the overall cost increases linearly, whereas the cost per part decreases in an exponential manner. This is expected because the indirect costs associated with the machines and tools are distributed to more parts. Comparing the two support strategies, it is noted that the difference in costs increases with increasing number of parts: At one part per build, the difference in overall cost is $15.30 €$ (Part B's cost is $112 \%$ of Part A's cost), while it is at $93.87 €$ for nine parts (Part B's cost is $118.5 \%$ of Part A's cost).

To determine the main cost driver of this use case, the contribution of the design, manufacturing, and removal costs is shown in Fig. 3. For a small number 


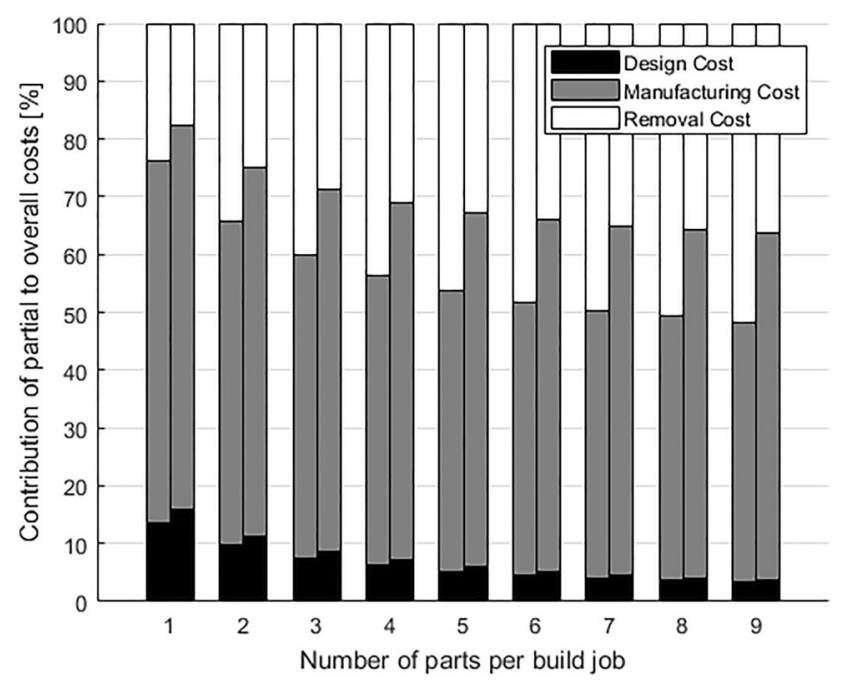

Fig. 3. Contribution of the respective process phases to the overall support structure cost. Left bar: part A, right bar: part $B$.

of parts, the manufacturing cost dominates. With increasing number of parts per build job, however, the cost of support structure removal becomes increasingly relevant. For Part A, the removal cost takes cost leadership over the manufacturing cost at six parts per build job, whereas the manufacturing cost remains the primary cost driver for Part B. This indicates that despite volume minimization being an important aspect of support structure optimization, the minimization of post-processing efforts is also highly relevant and may require more attention. Especially with PBF-LB/M extending its applications from small to larger volume production, the scaling of manufacturing and removal costs must be taken into account. The design cost of both parts is comparatively low, pointing out the admissibility of time-intensive support structure design procedures even at low production volume.

The support structure cost model consists of many input parameters. The most sensitive are the times for design and removal because these tasks are carried out by a human operator, inflicting the potential of great variance for the same task. To investigate both influences on the overall support structure cost, a sensitivity analysis is conducted. In the present use case, the design of the support structure was done by an expert in the field with years of experience. Thus, it is assumed that the expert took the minimum time possible to design the support structures of both parts. To examine the scaling effect, the cost of a build job consisting of nine equal parts is calculated with up to triple the design time (15 to 45 min for Part A, 20 to 60 min for Part B). The cost of design increases linearly by $5.48 € / 5 \mathrm{~min}$, which is equal to a rise in overall cost by $6.5 \%$ (Part A) and $7.3 \%$ (Part B), respectively. This demonstrates again that the efficiency of computational design is already at a high level, leading to relatively low impact on the support structure cost. Of course, the experience of a design expert is not well represented in the cost model. It is much more important for the design expert to be right about the support structure layout, therefore preventing build failure, than to be quick about it. The cost of possible build failure due to design errors in support structures is difficult to quantify, though. A possible solution to this limitation is a statistical approach to the number of critical mistakes a design expert is making throughout a defined period. However, this approach does not fit the calculative nature of the cost model, creating the need to adjust the cost model.

While the design of the support structures was done by an expert, the manual removal of the support structures was performed by a beginner. In accordance with the procedure applied for the design time sensitivity analysis, the time recorded for the use case is set as the maximum period necessary for support structure removal, resulting in evaluated time intervals of $5-25 \mathrm{~min}$ (Part A) and $10-30$ min (Part B). A 5-min change in the removal time leads to a cost decrease of $43.68 €$, again scaling linearly. Considering the full-time interval investigated, a reduction of Part A and B's overall support structure cost by $34.4 \%$ and $29.1 \%$, respectively, is achieved. Compared to the design time, these numbers are significantly higher despite the wage of the operator being lower. This finding shows the high potential of expert technical training and even automated support structure removal.

\section{COST ASSESSMENT IN SUPPORT STRUCTURE OPTIMIZATION}

To be able to assess the support structure-related costs is important to achieve the goal of cost reduction in support structure optimization. Therefore, the developed cost model is added to the benchmark procedure presented in an earlier study. Here, a benchmark procedure based on five parts specially designed to compare support structure performance has been proposed. For further details on the design of the parts, the reader is referred to (Ref. 11). For validation, the case of block and cone supports is applied, as those are common support structures with well-known characteristics. These characteristics were demonstrated in the benchmark: While block supports have a higher shear resistance and require more material, cone supports have a higher tensile strength and dissipate more heat. Cone supports are harder to remove manually, though.

In terms of economic evaluation, single parameters were used as cost indicators: material consumption, removal time, additional post-processing time, ease of removal, and surface quality after removal. These cost indicators are replaced by a full cost assessment. The parts were manufactured with a SLM500HL machine (SLM Solutions AG, Lübeck, Germany). To simplify this study, the calculation is performed for the M270 system introduced in Chap. 
Table II. Summary of individual cost model input parameters for benchmark validation.

\begin{tabular}{lccc}
\hline Parameter & Block support & & Cone support \\
$\begin{array}{l}\text { Support volume } \\
V\end{array}$ & $24,602 \mathrm{~mm}^{3}$ & & $17,232 \mathrm{~mm}^{3}$ \\
Difference height & & & \\
$\Delta h$ & & & \\
Additional wire eroding distance & & \\
$d_{\mathrm{W}}$ & & $0 \mathrm{~mm}$ & \\
Design time & $60 \mathrm{~min}$ & & $60 \mathrm{~min}$ \\
$t_{\mathrm{D}}$ & & & \\
Removal time & $57 \mathrm{~min}$ & & $82 \mathrm{~min}$ \\
$t_{\mathrm{R}}$ & &
\end{tabular}

3 , though. The individual input parameters to the cost model are given in Table II. As only the automatic solution of the design software is evaluated, the design time is equal for both support structure types. As the set of five parts is supposed to be evaluated together, it is treated as one single part.

The block support overall cost is calculated to be $322.74 €$, which is differentiated into $65.72 €$ $(20.36 \%)$ design cost, $201.70 €(62.50 \%)$ manufacturing cost, and $55.32 €(17.14 \%)$ post-processing cost. For the cone support, an overall cost of $286.57 €$ is derived, where the contribution of the design cost is $65.72 €(22.93 \%), 141.27 €(49.30 \%)$ is due to manufacturing, and $79.58 €(27.77 \%)$ is associated with the support structure removal. In conclusion, the generally higher performance of the cone support during manufacturing is associated with a significantly higher removal cost. However, the lower volume results in an overall lower support structure cost.

\section{CONCLUSION}

Efforts in research are being made to reduce the cost due to support structures in PBF-LB/M. For cost indication, mainly the volume of the support structures is used, but no detailed quantification of the actual costs is done. To help solve this issue, this work presented a calculative cost model for support structures as addition to an already proposed benchmark procedure to enable the comparison of support structure performance. Furthermore, a case study to demonstrate the use of the cost model to optimize support strategies is conducted. Both studies revealed a large influence of the support structure removal on the overall costs of the support structures, demonstrating that support structure optimization only regarding the support structure volume is not valid in every case. Future optimization of either the utilization of existing support structures or the development of new structures should include the overall costs.

The presented cost model is still open for improvement. By now, only build jobs with a single part geometry is considered. To enhance the cost model further, the possibility of various parts in one build job can be included. Additionally, it would be of great use to develop the model into a predictive cost model, enabling the product development to incorporate the different aspects of support structures in an early stage of design already. However, this would require a long-term study as well as the statistical evaluation of an enormous amount of build jobs and parts.

\section{FUNDING}

Open Access funding enabled and organized by Projekt DEAL.

\section{CONFLICT OF INTEREST}

The authors declare that they have no conflict of interest.

\section{OPEN ACCESS}

This article is licensed under a Creative Commons Attribution 4.0 International License, which permits use, sharing, adaptation, distribution and reproduction in any medium or format, as long as you give appropriate credit to the original author(s) and the source, provide a link to the Creative Commons licence, and indicate if changes were made. The images or other third party material in this article are included in the article's Creative Commons licence, unless indicated otherwise in a credit line to the material. If material is not included in the article's Creative Commons licence and your intended use is not permitted by statutory regulation or exceeds the permitted use, you will need to obtain permission directly from the copyright holder. To view a copy of this licence, visit $h$ ttp://creativecommons.org/licenses/by/4.0/.

\section{APPENDIX}

See Table III. 
Table III. Data input to the cost model

\begin{tabular}{|c|c|c|c|c|}
\hline Parameter & Value & Unit & Description & Source \\
\hline \multicolumn{5}{|l|}{ Operators } \\
\hline$c_{w, g, D}$ & $46,366.03$ & $€ / a$ & Annual gross wage of design engineer & (Ref. 25), E13 St. \\
\hline$c_{w, g, R}$ & $39,986.54$ & $€ / a$ & Annual gross wage of technician & (Ref. 25), E11 St. \\
\hline$c_{w, i, D}$ & 34.60 & $€ / h$ & Average incidental wage 2018 (Germany) & (Ref. 26) \\
\hline \multicolumn{5}{|l|}{$c_{w, i, R}$} \\
\hline$d_{\text {Year }}$ & 219 & $d / a$ & Workdays per year in 2018 (Germany) & (Ref. 27) \\
\hline$d_{\text {Week }}$ & 5 & $\mathrm{~d} /$ week & Average workdays per week in 2018 (Germany) & (Ref. 27) \\
\hline \multicolumn{5}{|c|}{ 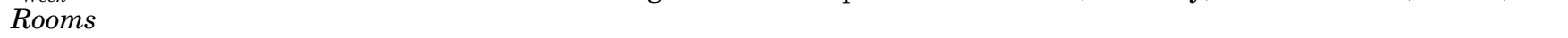 } \\
\hline$u_{O}$ & 5,256 & $\mathrm{~h} / \mathrm{a}$ & Utilization office room, all workdays per year & Estimation \\
\hline$A_{O}$ & 3 & $\mathrm{~m}^{2}$ & Standard office desk including room for chair $(2 \mathrm{~m} \times 1.5 \mathrm{~m})$ & Estimation \\
\hline$A_{M}$ & 12.6 & $\mathrm{~m}^{2}$ & $\begin{array}{l}\text { Space for LPBF machine including room for technician } \\
\qquad(3.5 \mathrm{~m} \times 3.6 \mathrm{~m})\end{array}$ & (Ref. 28) \\
\hline$A_{W}$ & 3 & $\mathrm{~m}^{2}$ & $\begin{array}{l}\text { Space for wire eroding machine including room for technician } \\
\qquad(1.5 \mathrm{~m} \times 2 \mathrm{~m})\end{array}$ & Estimation \\
\hline$u_{W S}$ & 2628 & $\mathrm{~h} / \mathrm{a}$ & Utilization of workshop & Estimation \\
\hline$A_{W S}$ & 2 & $\mathrm{~m}^{2}$ & Standard workbench including space for technician $(2 \mathrm{~m} \times 1 \mathrm{~m})$ & Estimation \\
\hline$c_{R R, O}$ & 14.9 & $€ / \mathrm{m}$ & Average rent of industrial space in Hamburg, Germany & (Ref. 29) \\
\hline \multicolumn{5}{|c|}{ 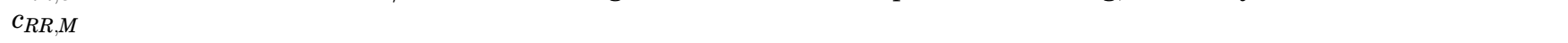 } \\
\hline \multicolumn{5}{|l|}{$c_{R R, W}$} \\
\hline \multicolumn{5}{|l|}{$c_{R R, W S}$} \\
\hline$c_{R O, O}$ & 3.11 & $€ / \mathrm{m}$ & Average operational cost of space in Hamburg, Germany & (Ref. 30) \\
\hline \multicolumn{5}{|l|}{$c_{R O, M}$} \\
\hline \multicolumn{5}{|l|}{$c_{R O, W}$} \\
\hline \multicolumn{5}{|l|}{$\begin{array}{l}c_{R O, W S} \\
\text { Software }\end{array}$} \\
\hline$u_{S W}$ & 2628 & $\mathrm{~h} / \mathrm{a}$ & Utilization of data preparation software & Estimation \\
\hline & 9000 & $€ / a$ & License cost of data preparation software & Quotation \\
\hline \multicolumn{5}{|c|}{ Computer hardware } \\
\hline$u_{H W}$ & 6570 & $\mathrm{~h} / \mathrm{a}$ & Utilization of computer hardware, can run overnight & Estimation \\
\hline$C_{I, H W}$ & 1000 & $€$ & Investment cost of computer hardware (Lenovo Thinkpad L470) & Quotation \\
\hline \multicolumn{5}{|c|}{ 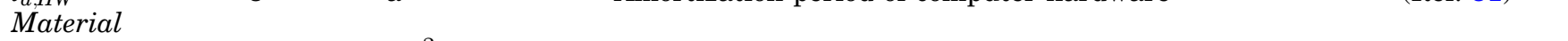 } \\
\hline$\rho$ & 4410 & $\mathrm{Kg} / \mathrm{m}^{2}$ & Density of Ti-6Al-4V & (Ref. 32) \\
\hline$c_{\text {Mat }}$ & 250 & $€ / \mathrm{kg}$ & Price of Ti-6Al-4V powder & (Ref. 18) \\
\hline$c_{\text {Scrap }}$ & 5 & $€ / \mathrm{kg}$ & Scrap price of solid titanium & (Ref. 33) \\
\hline \multicolumn{5}{|c|}{$P B F-L B / M$ machine EOS M270 } \\
\hline$u_{M}$ & 4380 & $\mathrm{~h} / \mathrm{a}$ & Utilization of PBF-LB/M machine, single shift production & Estimation \\
\hline$C_{I, M}$ & 500,000 & $€$ & Investment cost of PBF-LB/M machine & (Ref. 18) \\
\hline$t_{a, M}$ & 5 & $\mathrm{a}$ & Amortization period of $\mathrm{PBF}-\mathrm{LB} / \mathrm{M}$ machine & (Ref. 34) \\
\hline$c_{M, S e r}$ & 30,000 & $€ / a$ & Service cost of PBF-LB/M machine & (Ref. 18) \\
\hline$\dot{M}$ & 10.8 & $\mathrm{Cm}^{3} / \mathrm{h}$ & Melting rate of $\mathrm{PBF}-\mathrm{LB} / \mathrm{M}$ machine & (Ref. 18) \\
\hline$t h$ & 30 & $\mu m$ & Layer thickness used for Ti-6Al-4V manufacturing & (Ref. 18) \\
\hline$t_{P}$ & 10 & $\mathrm{~s}$ & Time for recoating of PBF-LB/M machine & (Ref. 18) \\
\hline$t_{D e l}$ & 2 & $\mathrm{~s}$ & Delay time of PBF-LB/M machine & (Ref. 18) \\
\hline$C_{I, F}$ & 335 & $€$ & Investment cost of $\mathrm{PBF}-\mathrm{LB} / \mathrm{M}$ machine filter & (Ref. 18) \\
\hline$t_{a, F}$ & 0.02 & $\mathrm{a}$ & Amortization period of filter & (Ref. 18) \\
\hline$c_{G}$ & 5 & $€ / h$ & Gas cost & $\begin{array}{l}\text { (Ref. 18), estima- } \\
\text { tion }\end{array}$ \\
\hline \multicolumn{5}{|l|}{ Energy } \\
\hline$E$ & 5.5 & $\mathrm{~kW}$ & Maximum energy consumption of PBF-LB/M machine & (Ref. 28) \\
\hline $\begin{array}{l}p_{E} \\
\text { Tools }\end{array}$ & 0.28 & $€ / k W h$ & Average energy price in Hamburg, Germany & Online \\
\hline$u_{T}$ & 1314 & $\mathrm{~h} / \mathrm{a}$ & Utilization of tools & Estimation \\
\hline$C_{I, T}$ & 500 & $€$ & Investment cost of one full set of tools & Online \\
\hline$t_{a, T}$ & 7 & $\mathrm{a}$ & Amortization period of tools & (Ref. 35) \\
\hline
\end{tabular}




\section{REFERENCES}

1. J. Kranz, D. Herzog, and C. Emmelmann, J. Laser Appl. 27(S1), S14001. https://doi.org/10.2351/1.4885235 (2015).

2. D. Wang, Y. Yang, Z. Yi, and X. Su, Int. J. Adv. Manuf. Technol. 65(9-12), 1471. https://doi.org/10.1007/s00170-0124271-4 (2013).

3. L.D. Bobbio, S. Qin, A. Dunbar, P. Michaleris, and A.M. Beese, Addit. Manuf. 14, 60. https://doi.org/10.1016/j.addma. 2017.01.002 (2017)

4. C. Wei, Y.-H. Chueh, X. Zhang, Y. Huang, Q. Chen, and L. Li, J. Manuf. Sci. Eng., 141, 7, p. 147 (2019), https://doi.org/ 10.1115/1.4043536.

5. M. Langelaar, Topology optimization for additive manufacturing with controllable support structure costs, in $E C C O$ MAS Congress 2016: VII European Congress on Computational Methods in Applied Sciences and Engineering: Proceedings pp. 3689 (2016).

6. M. Langelaar, Struct. Multidisc. Optim. 57(5), 1985. http s://doi.org/10.1007/s00158-017-1877-z (2018)

7. M. Langelaar, RPJ 25(2), 255. https://doi.org/10.1108/RPJ12-2017-0246 (2019).

8. Y.-H. Kuo, C.-C. Cheng, Y.-S. Lin, and C.-H. San, Struct. Multidisc. Optim. 57(1), 183. https://doi.org/10.1007/s00158 017-1743-z (2018).

9. Z. Zhang, C. Wu, T. Li, K. Liang, and Y. Cao," RPJ, 24, 4, pp. 764 (2018). https://doi.org/10.1108/RPJ-11-2016-0186.

10. T. Künneke, T. Lieneke, S. Lammers, and D. Zimmer, "Design Guidelines For Post-Processing Of Laser Beam Melting in Context Of Support Structures, in Joint Special Interest Group meeting between euspen and ASPE "Advancing Precision in Additive Manufacturing", Nante, France (2019), [Online]. Available: https://www.euspen.eu/ knowledge-base/AM19127.pdf.

11. K. Bartsch, J. Ohrenberg, and C. Emmelmann, Procedia CIRP 94(9), 254. https://doi.org/10.1016/j.procir.2020.09.048 (2020).

12. J.-P. Rudolph, Cloudbasierte Potentialerschließung in der additiven Fertigung. Berlin, Heidelberg: Springer Berlin Heidelberg (2018).

13. T. Schmidt, Potentialbewertung generativer Fertigungsverfahren für Leichtbauteile. Berlin, Heidelberg: Springer (2016).

14. M. Baldinger, G. Levy, P. Schönsleben, and M. Wandfluh, RPJ 22(6), 871. https://doi.org/10.1108/RPJ-02-2015-0023 (2016).

15. P. Alexander, S. Allen, and D. Dutta, Comput. Aided Des. 30(5), 343. https://doi.org/10.1016/S0010-4485(97)00083-3 (1998).

16. E. Atzeni, and A. Salmi, Int. J. Adv. Manuf.Technol. 62(912), 1147. https://doi.org/10.1007/s00170-011-3878-1 (2012).

17. M. Baumers, C. Tuck, R. Wildman, I. Ashcroft, E. Rosamond, and R. Hague, Combined build-time, energy consumption and cost estimation for direct metal laser sintering. In: Proceedings of the Solid Freeform Fabrication Symposium, Austin, USA, 2012, pp. 932.

18. J. Kranz, Methodik und Richtlinien für die Konstruktion von laseradditiv gefertigten Leichtbaustrukturen. Berlin, Heidelberg: Springer (2017).

19. H. Piili, A. Happonen, T. Väistö, V. Venkataramanan, J. Partanen, and A. Salminen, Phys. Procedia 78, 388. https://d oi.org/10.1016/j.phpro.2015.11.053 (2015).
20. M. Ruffo, and R. Hague, Proceedings of the institution of mechanical engineers. Part B J. Eng. Manuf. 221(11), 1585. https://doi.org/10.1243/09544054JEM894 (2007).

21. V. Griffiths, J.P. Scanlan, M.H. Eres, A. Martinez-Sykora, and P. Chinchapatnam, Eur. J. Oper. Res. 273(1), 334. h ttps://doi.org/10.1016/j.ejor.2018.07.053 (2019).

22. R.E. Laureijs, J.B. Roca, S.P. Narra, C. Montgomery, J.L. Beuth, and E.R.H. Fuchs, J. Manuf. Sci. Eng. 139(8), 499. h ttps://doi.org/10.1115/1.4035420 (2017).

23. C. Lindemann, U. Jahnke, M. Moi, and R. Koch, Impact and influence factors of additive manufacturing on product lifecycle costs. In: Proceedings of the Solid Freeform Fabrication Symposium, Austin, USA, pp. 998 (2013).

24. L. Rickenbacher, A. Spierings, and K. Wegener, Rapid Prototyp. J. 19(3), 208. https://doi.org/10.1108/13552541311 312201 (2013).

25. Collective Agreement TV-L West. [Online]. Available: http:// oeffentlicher-dienst.info/c/t/rechner/tv-l/west?id=tv-l-2019. Accessed 25 Jan 2021.

26. Eurostat, Labour costs annual data, TPS00173 (2018), [Online]. Available: https://ec.europa.eu/eurostat/databrows er/view/tps00173/default/table?lang=en. Accessed 19 Oct 2019.

27. Institute for Employment Research, Average working hours and their components (2019), [Online]. Available: https://w ww.iab.de/en/daten/iab-arbeitszeitrechnung.aspx. Accessed 19 Oct 2019.

28. EOS GmbH Electro Optical Systems, EOSINT M270 data sheet. [Online]. Available: https://dmlstechnology.com/image s/pdf/EOSINT_M_270.pdf. Accessed 19 Oct 2019.

29. Gutachterausschuss für Grundstückswerte in Hamburg, Immobilienmarktbericht Hamburg (2018), [Online]. Available: http://daten-hamburg.de/infrastruktur_bauen_wohne n/immobilienmarktberichte/IMB2018.pdf Accessed 25 Jan 2021.

30. Deutscher Mieterbund e.V., Betriebskostenspiegel für Hamburg (2015), [Online]. Available: https://www.mieterve rein-hamburg.de/export/sites/default/.content/dokumente/b etriebskostenspiegel/BKS_AJ2015_Hamburg.pdf Accessed 25 Jan 2021.

31. Federal Ministry of Finance Germany, Fiscal Deprication Table Assets for general use, IV D 2-S 1551 (2000).

32. EOS GmbH Electro Optical Systems, Material data sheet EOS Titanium Ti64. (Online). Available: https://www.fabbit.de/files/datenblaetter/titan.pdf. Accessed 19 Oct 2019.

33. Recyclinghütte, Kurse und Ankaufpreise. (Online). Available: http://www.metallankauf-recycling.de/ankaufspreis/. Accessed 19 Oct 2019.

34. Federal Ministry of Finance Germany, Fiscal Deprication Table Mechanical Engineering, IV D 2-S 1551 (2001).

35. Federal Ministry of Finance Germany, Fiscal Deprication Table Iron and Metal Working Industry, IV A 8-S 1551 (1997).

Publisher's Note Springer Nature remains neutral with regard to jurisdictional claims in published maps and institutional affiliations. 